\title{
Some Characteristics of Syllable Structure in Qassimi Arabic (QA): An Optimality Theoretic Framework
}

\author{
Mohammad Aljutaily ${ }^{1} \&$ Metab Alhoody ${ }^{1}$ \\ ${ }^{1}$ Department of English Language \& Translation, College of Arabic Language \& Social Studies, Qassim \\ University, Saudi Arabia \\ Correspondence: Mohammad Aljutaily, Department of English Language \& Translation, College of Arabic \\ Language \& Social Studies, Qassim University, Saudi Arabia. E-mail: mjtiely@qu.edu.sa
}

Received: May 3, 2020

Accepted: June 5, $2020 \quad$ Online Published: June 7, 2020

doi:10.5539/ijel.v10n4p193

URL: https://doi.org/10.5539/ijel.v10n4p193

\begin{abstract}
The paper investigates the syllable structures of Qassimi Arabic (QA), which is a sub-dialect of Najdi Arabic (NA) and is spoken in the north-central region of Saudi Arabia, particularly in the Qassim Region. Within the framework of Optimality Theory (OT), we show how the well-formed syllable is derived from the interaction of constraints. We show how the OT captures some of the major processes for structuring the syllables of QA, such as syncope, epenthesis, and geminate. The analysis revealed that onsetless syllables are prohibited in QA. The dialect allows word-initial consonant clusters, which is a result of the syncope process. Coda clusters also occur in QA that must obey the Sonority Sequencing Principle (SSP); otherwise, epenthesis presents to repair the violation. As for the geminates, QA permits geminates medially and finally, but not initially. The data revealed that QA demonstrates seven fundamental syllable structures grouped into three categories: light syllables, as in $\mathrm{CV}$; heavy syllables, as in CVV and CVC; and super heavy syllables, as in CVVC, CVCC, CCVVC and CVVCC.
\end{abstract}

Keywords: optimality theory, consonant cluster, syncope, geminate, Qassimi Arabic

\section{Introduction}

Syllable structure is a sequence of segments that function as a unit. This sequence is often a collection of consonants and vowels. Maximally, it comprises an onset, nucleus, and coda; minimally, it comprises a nucleus (Reetz \& Jongman, 2009). The syllable is shaped differently from language to language; whereas some languages permit clusters in both or either margins, other languages do not. For instance, English has clusters at both boundaries, Finnish has clusters only in the coda position, and Fijian does not allow any clusters at the boundaries (Kreidler, 2001). In most cases, the segments of the syllable are organized and motivated by the sonority hierarchy, that is, the segments are grouped in a syllable according to their hierarchic scale. Reetz and Jongman (2009) ranked sonority from the most to least sonorous as follows: vowels (most sonorous) $\rightarrow$ approximant $\rightarrow$ nasal $\rightarrow$ fricative $\rightarrow$ stops (least sonorous). They state that a syllable is linked with a peak in sonority and that the sonority rises towards the syllable nucleus and descends towards syllable coda. This characteristic is called the Sonority Sequencing Principle (SSP).

\subsection{Universal Syllable Structure}

There are specific syllable structures that are preferred cross-linguistically over other structures. According to Kager (1999), it is preferred that the syllable start with a consonant and end with a vowel. Kreidler (2001) confirms this assertion when he states that "all languages have CV syllables" (p. 86). Therefore, the core structure of the syllable is a sequence of consonant and vowel. Alghmaiz (2013) states that "there is a consensus among most linguistic researchers that $\mathrm{CV}$ syllable is an absolute universal syllable pattern across all world languages" (p. 6). Well-known syllable structures that occur in all languages are V, CV, CVC, and VC (Clements \& Keyser, 1983).

\subsection{General Overview of Qassimi Arabic and Syllable Structure}

The Qassimi dialect is a sub-dialect of the Najdi Arabic dialect, which is spoken in the north-central region of Saudi Arabia, particularly in the Qassim Region. Qassimi Arabic is distinct from both Modern Standard Arabic (MSA) and Classical Arabic (CA) (Note 1) and differs from these versions in terms of certain structural positions. 
For example, the structure CVVC appears in final and non-final positions in QA, as in the word saak.tiin "They were silent," while this structure occurs only finally in MSA and CA. Additionally, initial consonant clusters are allowed in QA but are not permitted in either MSA or CA. However, there are commonalities between these variations, such as the existence of optional coda and the prohibition of onsetless syllables. All the syllable shapes that occur in MSA and CA exist in QA as well, but not vice versa. The overall syllable shapes in CA and MSA are found in Jarrah (2013) as CV fahı "tea," CVV kaatıb "writer," CVC kas "cup," CVVC daxaan "smoke," and CVCC farq "east."

\subsection{Review of Related Literature}

A number of studies have investigated the syllable structures of Arabic in general. For example, McCarthy (1979a) investigated the stress placement in Classical Arabic and showed how the stress is identified by syllable weight and position. Studies also exist on Arabic dialects that are spoken in some Arab countries, such as Hamdi et al. (2005), who conducted a comparative study on three Arabic dialects: Moroccan spoken in Morocco, Tunisian spoken in Tunis, and Lebanese spoken in Lebanon. The study observed the different syllable structures of these dialects and focused on complexity clusters occurring in the boundaries. Aquil (2013) and Broselow (1979) investigated the syllable structure of Cairene Arabic spoken in Egypt. Benhallam (1980) investigated the syllable structure of Moroccan Arabic and showed how specific phonological rules exert an effect on syllable structure.

In addition to these studies, some studies have investigated syllable structures of varieties or sub-dialects of Arabic that appear in some regions of Arab countries. For instance, Moroccan Arabic has some varieties that are spoken in different parts of Morocco, such as the Casablancan Arabic that is spoken in Casablanca, Saudi Arabic has the Najdi dialect and the Hijazi dialect, etc. Btoosh (2006) studied the phonotactics of Karak Arabic, which is a variety of Jordanian Arabic that is spoken in the middle part of Jordan. Btoosh illustrated the behavior of complex margins with respect to faithfulness and markedness constraints. In terms of Saudi Arabic, Jarrah (2013) investigated the syllable structure of Madina Hijazi Arabic, which is spoken in Madina city in Saudi Arabia. He illustrated how the interaction of constraints results in syllabic well-formedness and demonstrates how the undominated constraint, such as an ONSET, is ranked highly and never violated. Furthermore, he showed that coda consonant clusters in Madina Hijazi Arabic obey sonority sequencing. Although no study to date has described the syllable structures in QA, some studies have been conducted on the syllable patterns of Najdi Arabic (NA), of which Qassimi Arabic is a sub-dialect. Qassimi Arabic demonstrates ample similarities between itself and its source (i.e., Najdi Arabic), so it stands to reason that we can rely on the available studies conducted on Najdi Arabic to inform the study of Qassimi Arabic. Ingham (1994) conducted a descriptive study of the Najdi dialect and stated that Najdi shares most of its phonemic inventory with that occurring in Classical Arabic. However, unlike Classical Arabic, Najdi allows initial onset clusters, which appear under CV metathesis, such as gah.wah "coffee," which surfaces as [gha.wah]. Some underlying final consonant clusters are syllabified by vowel insertion, particularly if the final clusters are composed of sonorant segments (i.e., m, n, l, r); for example, $\hbar a m l$

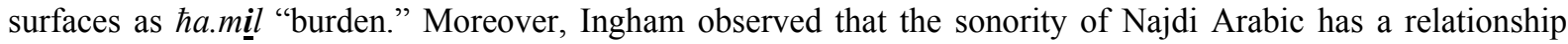
with the syllable structure. Abboud (1979) investigated the syllabification and the stress of verbs in Najdi Arabic. Al-Sweel (1987) provided general ideas about phonological aspects in NA such as consonants, vowels, vowel epenthesis, and deletion.

More recently, Alghmaiz (2013) conducted a study on syllables of NA. His work is specific to initial consonant clusters found in Najdi Arabic/dialect. He observed that not all manners of articulation of the consonants could be grouped together in initial consonant clusters. The sequence of clusters that includes stop and glide or fricative and glide are not allowed, and the speaker of NA tends to insert a vowel between the clusters. In other words, he explains these restrictions by relying on sonority distance. He states that there are three intervals between fricative and glide, and, consequently, this structure motivates epenthesis and block syncope. Similarly, grouping stop and glide together results in four intervals, thereby motivating epenthesis.

\subsection{Consonant Inventory in Qassimi Arabic}

In this section, we provide a brief overview of the consonant system in QA. Table 1 exhibits the consonantal phonemes of this variety, which is composed of 29 consonants. The table illustrates both the place and manner of articulation of this variety. The top sound is voiceless, whereas the bottom one is voiced. 
Table 1. Qassimi Arabic consonants

\begin{tabular}{|c|c|c|c|c|c|c|c|c|c|c|}
\hline & Bilabial & Labiodentals & Dental & $\begin{array}{l}\text { Alveolar } \\
\text { (Emphatic) }\end{array}$ & Alveo-Palatal & Palatal & Velar & Uvular & Pharyngeal & Glottal \\
\hline \multirow[t]{3}{*}{ Stops } & b & & & t & & & $\mathbf{k}$ & & $q$ & $?$ \\
\hline & & & & d & & & g & & & \\
\hline & & & & $\mathbf{t}^{\mathrm{s}}$ & & & & & & \\
\hline \multirow[t]{3}{*}{ Fricative } & & f & $\Theta$ & s & J & & & $\mathbf{x}$ & $\mathbf{h}$ & h \\
\hline & & & ð & $\mathbf{z}$ & & & & в & ؟ & \\
\hline & & & $\jmath^{\varsigma}$ & $\mathbf{s}^{\mathrm{s}}$ & & & & & & \\
\hline \multirow[t]{2}{*}{ Affricative } & & & & ts & $d_{3}$ & & & & & \\
\hline & & & & $\mathrm{dz}$ & & & & & & \\
\hline Nasal & $\mathbf{m}$ & & & $\mathbf{n}$ & & & & & & \\
\hline Trill & & & & $\mathbf{r}$ & & & & & & \\
\hline Approximants & $\mathbf{w}$ & & & & & $y=j$ & & & & \\
\hline Lateral & & & & 1 & & & & & & \\
\hline
\end{tabular}

As shown in the previous table, QA exhibits twenty-nine consonants, as opposed to CA and MSA, which have twenty-eight consonants. All the consonants of CA and MSA appear in QA except the alveolar emphatic voiced stop $/ \mathrm{d}^{\mathrm{q}} /$. QA also preserves the three distinctive classes that occur in MSA and CA, namely, emphatic, uvular and pharyngeal sounds, which do not appear in most languages. According to Newman (2008), "Arabic is one of only thirty-five languages within UPSID to have stop phonemes in five different places of articulation" (p. 66). QA and other Arabic dialects do not have the voiceless bilabial stop $/ \mathrm{p} /$, though some studies of Arabic phonology, such as Qafisheh (1977), include it as a phoneme in the inventory. Naess (2008) states that /p/ exists in specific loanwords borrowed from Persian. Kaye and Daniels (1997) claim that the voiced bilabial stop /b/ is devoiced in Arabic if it is followed by a voiceless sound. For instance, the speakers of Arabic pronounce the voiced bilabial stop in the word /kabs/ "push" as a voiceless bilabial stop. In addition, QA has three unique phonemes that are so-called emphatic sounds $/ \nearrow^{\varsigma}, \mathrm{t}^{\mathrm{s}}, \mathrm{s}^{\mathrm{s}} /$ and three affricates $/ \mathrm{dz}, \mathrm{ts}, \mathrm{d} 3 /$. Furthermore, the voiceless uvular stop /q/ (i.e., the Classical Arabic version) is considered an unstable sound in many Arabic dialects. In QA, it could be realized mostly as a voiced velar stop /g/, except in words that are borrowed from Classical Arabic; for example, in the word /qur.Paan/ "Qur'an" (Islamic religious text), it would be realized as /q/. As we have mentioned above, QA includes many of the Classical Arabic and Modern Standard Arabic features; therefore, most of their consonants are preserved in QA. Nevertheless, sounds such as the emphatic (voiced-alveolar-stop) / $\mathrm{d}^{\S} /$ disappeared in QA. QA, like its source NA (Najdi Arabic), differs from Classical Arabic and Modern Standard Arabic in the emphatic consonants, in which the emphatic (voiced-alveolar-stop) $/ \mathrm{d}^{\mathrm{s} /}$ that occurs in the Classical Arabic is merged with emphatic (voiced-dental-fricative) $/ \delta^{\varsigma} /$ and becomes $/ \delta^{\varsigma} /$. Naess (2008) states that the disappearance of the emphatic phoneme / $\mathrm{d}^{\varsigma} /$ from NA resulted from the merger of $/ \mathrm{d}^{\S} /$ and $/ \mathrm{d}^{\varsigma} /$, thereby becoming $/ \widehat{\delta}^{\varsigma} /$. As for the glottal stop, it was lost medially from words of QA. Ingham (1994) claims that the glottal stop does not exist medially in NA, except in a few words that are borrowed from Classical Arabic, for instance, the word /qur.Paan/ 'Qur'an' (Islamic religious text).

\section{Data}

The following data set is presented and syllabified by the authors of this paper, who are native speakers of this dialect. Two native speakers of Qassimi Arabic have also verified it. Both were born and brought up in the Qassim Region and speak its dialect. We presented the data set to the speakers and asked them to divide the words into their constituent syllables. Both of the speakers are studying Linguistics and have knowledge in how to syllabify the words. We excluded the words that were syllabified differently and listed only the unanimous structure as demonstrated below (The dot "." indicates the syllable boundary). 
Table 2. Some words spoken in Qassimi Arabic

\begin{tabular}{|c|c|c|}
\hline $\mathrm{CV}$ & 24. Prk.trb 'write' & CVVC \\
\hline 1. hu 'He' & 25. kas 'cup' & 47. kab.buut 'bonnet' \\
\hline 2. fi 'in' & 26. mu.dar.ris 'teacher' & 48. daab 'snake' \\
\hline 3. ga.lam 'pen' & 27. хıð ‘take’ & 49. biir 'well' \\
\hline 4. Ja.hr 'tea' & 28. mas.d3rd 'mosque' & 50. fiif 'outlet' \\
\hline 5. dzæ.mid 'frozen' & 29. dzaw.wal 'cell phone' & 51. dax.xaan 'smoke' \\
\hline 6. kir.sI 'chair' & 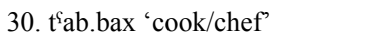 & 52. da.liil 'guidebook' \\
\hline 7. ta.rix 'date/history' & CVV (Note 2) & 53. ma.riiðৎ 'patient' \\
\hline 8. ra.bi 'stupid' & 31. xaa.lı 'uncle' & 54. Suug 'market' \\
\hline 9. bin.ti.na 'our daughter' & 32. dzaa.rI 'my neighbor' & 55. $\mathrm{s}^{\text {`a.laat ' }}$ prayer' \\
\hline 10. s'a.rir 'small' & 33. dı.rii. əəh 'window' & 56. mas.yuul 'busy' \\
\hline 11. hr 'she' & 34. haa.li 'very sweet' & 57. saak.tiin 'They were silent' \\
\hline 12. Ja.rab 'he drank' & 35. lii 'it is mine' & 58. gi.riib 'very close' \\
\hline 13. za.wadz 'marriage' & 36. kı.taa.bi 'my book' & 59. nı.d'iif 'clean' \\
\hline 14. so.hil 'easy' & CVCC & 60. nuur 'illumination' \\
\hline 15. sa.fər 'travel (n)' & 37. lamb.bəh 'lamp' & CCVVC \\
\hline 16. mi.riðs 'patient (n)' & 38. milh 'salt' & 61. ktaab 'book' \\
\hline CVC & 39. dzıld 'leather' & 62. traab 'sand' \\
\hline 17. mak.tab 'office' & 40. $t^{\mathrm{s}}$ alb 'dog' & 63. fraa 'bed' \\
\hline 18. PIm.sah 'delete' & 41. galb 'heart' & 64. ðnuub 'sins’ \\
\hline 19. rah 'left' & 42. bint 'girl' & 65. hmaar 'donkey' \\
\hline 20. s`al.la 'he prayed' & 43. $\mathrm{mI} \mathrm{ft}^{\mathrm{t}}$ 'comb' & CVVCC \\
\hline 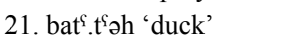 & 44. kI.tabt 'I wrote' & 66. haadd 'sharp' \\
\hline 22. lam.maS 'polished.(v)' & 45. harf 'letter' & 67. dzaadd 'earnest' \\
\hline 23. Pas $^{\varsigma}$.far 'yelow' & 46. saa.maht.hum 'forgive them' & 68. Saamm 'general' \\
\hline
\end{tabular}

\section{The Syllable Structure of the Qassimi Arabic}

Before discussing the syllable structures of QA, it is helpful to provide a brief overview of the stress placement in QA. QA is a quantity-sensitive dialect that relies substantially on the heaviness of the syllables to determine stress positions, as in Classical Arabic (McCarthy, 1979). Stress falls finally in QA if the syllable is CVVC, as in kaat.biin "they wrote," or CVCC, as in ka.tabt "I wrote." Otherwise, the rightmost heaviest syllables always attract stress, as shown in ki.taa.bi "my book." In disyllabic words, particularly in the absence of heavy syllables, stress falls on the penultimate, as in ka.tab "he wrote"; otherwise, the antepenultimates favor stress, as exemplified in ku.tu.bi "my books."

According to the above-mentioned data, Qassimi Arabic shows seven syllable structures. These structures are demonstrated below with their representations:

\section{CV \\ 2. CVV \\ 3. $\mathrm{CVC}$ \\ 4. CVCC \\ 5. CCVVC \\ 6. CVVCC 7. CVVC}
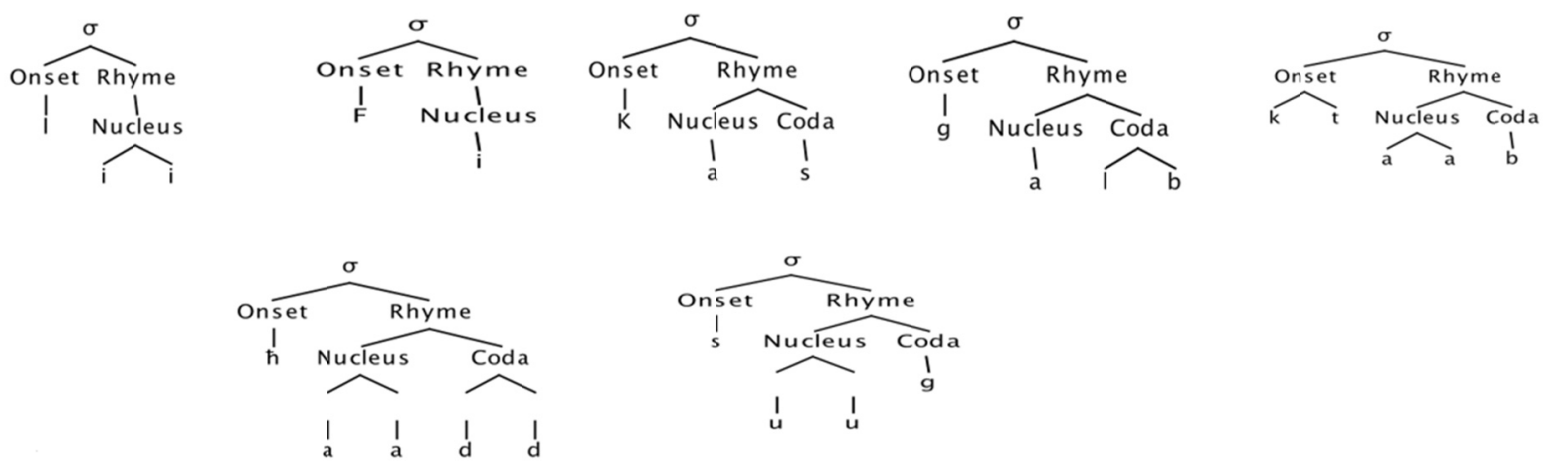

The data reveal several facts about the syllable structure of Qassimi Arabic. QA includes the light syllable CV (i.e., monomoraic syllable); heavy syllables CVV, CVC (i.e., bimoraic syllable); and super-heavy syllables CVCC, CVVC, CCVVC and CVVCC (i.e., three or more moras syllables). Furthermore, each syllable must have an onset, in which the syllable is never started with a vowel. According to Aquil (2013), Kager (1999), and 
Abboud (1979), the syllables with no onsets are prohibited in Classical Arabic. Aljumah (2008) states that “onsetless syllables are prohibited in most, if not all, Arabic dialects" (p. 159). As demonstrated by the previous structures, QA does allow word-initial consonant clusters. QA is distinguished from the Classical Arabic in having initial consonant clusters word-initially, as in data (62) and (63) traab "sand" and fraaf "bed," respectively. The initial consonant clusters in CCVVC surface from CVCVVC firaa "bed" and toraab "sand" under a syncope process, which we will discuss later, in the syncope section. In addition, the nucleus (i.e., vowel) is required in each syllable. Ingham (1994) states that the nucleus in all syllable types of Arabic must be a vowel, which is not surprising because the nucleus is obligatory cross-linguistically (Kager, 1999). From the structures illustrated above, the coda in QA is optional, as is the case in English, and complex codas are allowed as well. QA allows complex coda clusters in words medially or finally, as in data (37) and (39) lamb.bəh "lamp" and dy 1 ld "leather," respectively. However, there are some coda clusters that have undergone epenthesis repairs, particularly the clusters that violate the SSP. For example, the surface form of the word gIdIr "pot" comes from the underlying form gIdr "pot," and this process will be detailed later under the epenthesis section. Geminates are also observed in the data. As with other modern Arabic dialects, QA allows geminates only in the middle and final positions but not initially. The final observation relates to the super-heavy syllables, particularly CVVC and CVCC. Broselow et al. (1995) states that the super-heavy syllables in Standard Arabic and most varieties of Arabic are prohibited word-medially and are restricted to the word-final position. However, QA shows that the super-heavy syllables CVVC and CVCC are permitted in two positions. First, they occur in the non-final position, as in the data (57) saak.tiin "They were silent" and in (46) saa.maht.hum "I forgive them." Second, they occur in the word-final position, as found in Standard Arabic and most modern Arabic varieties; for example, the syllable CVVC can be seen in the data (58) gI.riib "very close" and the syllable CVCC in the data (44) ka.tabt "I wrote."

\section{Analysis within an Optimality Theoretical Framework}

This section provides a brief overview of Optimality Theory (OT), proposed by Prince and Smolensky (1993). Unlike the theory of generative phonology, OT depends on the interaction of constraints rather than on rules. The OT generates surface representations from underlying forms without intermediate steps/rules. In fact, its grammar consists of universal constraints (i.e., markedness and faithfulness), which are similar across languages. That is, the phonologies of all languages share the same constraints, but the ranking of those constraints differs from language to language. The ranking is attributed to the phonology of the language; differences in grammar reflect different rankings of the universal constraints. For instance, since QA does not allow vowel-initial syllables, the constraint ONSET is ranked highly in QA, but the same constraint is ranked as low in a language that permits onsetless syllables, such as English. From the underlying representation, the generator (GEN) randomly manipulates the underlying form and generates a candidate set. Then, the evaluator (EVAL) evaluates the candidate sets and determines the most harmonic output according to the constraint hierarchy of the language. Structurally, McCarthy (2008) provides a view of the OT as:

Input $\rightarrow$ GEN $\rightarrow$ Candidates $\rightarrow$ EVAL $\rightarrow$ Optimal Output (McCarthy, 2008). In the subsequent sections, we show how OT captures some of the syllable structure processes in QA, such as syncope, epenthesis, and geminates. To account for the previous processes, we need eight essential universal constraints. These constraints are explained below:

Markedness Constraints:

ONSET: "Syllables must have onsets"

(Kager, 1999, p. 93)

NO-CODA: "Syllables are open"

(Kager, 1999, p. 94)

COMPLEX: "No complex syllable margins"

(Kager, 1999, p. 288)

SONORITY SEQUENCING PRINCIPLE (SSP): "Sonority increases towards the syllable peak and decreases towards the syllable margins"

(Jarrah, 2013, p. 8)

$\left.*_{\mathrm{i}}\right]_{\sigma}$ : high short unstressed vowel in open syllable is banned

(Rakhieh, 2009)

$\mu]_{\sigma}$ GEM. $[\mu$ : No geminates splitting

(Aljumah, 2008, p. 174)

Faithfulness Constraints

(Kager, 1999, p. 93)

MAX-IO: "Input segments must have output correspondents" No deletion.

DEP-IO: "Output segments must have input correspondents" No epenthesis. 


\section{Syncope in QA}

Syncope (deletion) is defined as the loss of an unstressed vowel from the interior of a word (Campbell, 2004). The syncope plays a role in structuring the syllable in most Arabic dialects, such as Bedouin Hijazi Arabic (Al-Mozainy, 1981), San'ani Arabic (Watson, 2002), and Jordanian Arabic (Sakarna, 2005). Likewise, the syncope has an effect on the syllable structure of QA, in which initial bi-consonantal clusters are created by deleting an unstressed vowel. For the sake of clarity, we repeat the data here so that we can maintain our focus on processes.
a. /hımaar/ $\rightarrow$ [hmaar] "donkey"
b./turaab/ $\rightarrow$ [traab] "sand"
c. /fi.raaf/ $\rightarrow$ [fraaf/ "bed"
d. $/$ ra.suul/ $\rightarrow$ [ra.suul] "messenger"

The data [hmaar] "donkey," [traab] "sand," and [fraaf] "bed" represent the CCVVC structure, which results from CVCVVC under a syncope process. As demonstrated by the previous data (a-c), QA, like most Arabic dialects, tends to target unstressed high short vowels ( $I$ and $u$ ) to create consonant clusters in the onset position. The data show that the vowel deletion targets unstressed high vowels in non-final syllables, which is preceded by the stressed syllable structure CVVC. Finally, the data (d)/ra. suul/ "messenger" surfaces as [ra.suul] without syncopating, though the first vowel meets the requirement of deletion (unstressed vowel in non-final light syllable). The vowel is not deleted because the word /ra. suul/ 'messenger' is a loanword from Standard Arabic, and as we mentioned earlier, Standard Arabic does not allow initial word consonant clusters and, consequently, does not syncopate unstressed vowels in non-final syllables. In his investigation of Ma'ani Arabic, a variety spoken in Jordan, Rakhieh (2009) noticed that Ma'ani Arabic allows initial word consonant clusters resulting from syncopating unstressed vowels in non-final syllables, as found in QA and some other modern Arabic dialects. Moreover, he observed that there are some words in Ma'ani Arabic that surface without deleting the

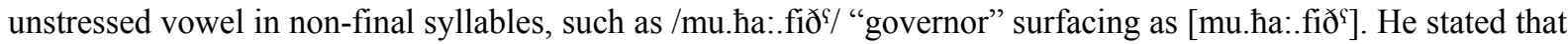
these words are borrowed from Standard Arabic, which does not allow the syncope that causes initial consonant clusters. Based on the data, the patterns of consonant clusters that could be grouped as word-initial clusters are the following: fricative plus liquid (\#fr), stop plus liquid (\#tr), fricative plus nasal (\#ћm, ðn), and stop plus stop (\#kt).

Now let us show how the syncope in QA is analyzed within the framework of OT. The following constraints in Table 3 are interacted to evaluate the candidates of the input /turaab/ "sand."

Table 3. ONSET $\left.>>*_{\mathrm{i}}\right]_{\sigma}>>$ COMPLEX $>>$ MAX-IO $>>$ DEP-IO

\begin{tabular}{llllll}
\hline$/$ turaab $/$ & ONSET & $*$ i $]_{\sigma}$ & COMPLEX & MAX-IO & DEP-IO \\
\hline a. traab & & & $*$ & $*$ & \\
b. tu.raab & & $* !$ & & $*$ & $*$ \\
c. a.t.raab & $* !$ & & & $*$ & $*$ \\
\hline
\end{tabular}

Table 3 illustrates that candidates (b) and (c) are eliminated because they fatally violate the first two highest-ranking constraints, ONSET and $\left.*_{\mathrm{i}}\right]_{\sigma}$ (i.e., they disallow the high short unstressed vowel in open syllables). Candidate (a) satisfies the high-ranked constraints ONSET and $\left.*_{i}\right]_{\sigma}$. Thus, candidate (a) is considered the optimal candidate.

\section{Epenthesis in QA}

Epenthesis (insertion) can be an anaptyxis (inserting a vowel) or excrescence (inserting a consonant) to the internal word. This mechanism is mostly used as a kind of syllable repair, for example, adding a vowel to break consonant clusters or adding a consonant to split a vowel in hiatus. The epenthesis process appears in Arabic and its dialects, occurring in either an initial position to create an onset, as in Arabic and its modern dialects, or in a coda position with clusters that violate sonority sequencing, as found in some of the Arabic dialects, such as Najdi Arabic (Ingham, 1994), Lebanese Arabic (Abdul-Karim, 1980), Medinah Hijazi Arabic (Jarrah, 1993), and Urban Hijazi Arabic (Al-Mohanna, 1998). As stated earlier, QA allows a complex coda in words medially or finally, as in data (37) lamb.bəh "lamp" and (39) dzIld "leather," respectively. However, some coda clusters have undergone epenthesis repairs, as found in certain modern Arabic dialects, particularly the clusters that violate the Sonority Sequencing Principle (SSP). The SSP means that the sonorous consonant must be closer to the syllable 
peak (nucleus), whereas the less sonorous consonants must be away from the peak. Consider the following data:

\begin{tabular}{|c|c|c|}
\hline e. /bint/ & $\rightarrow \quad$ [bint $]$ & “daughter" \\
\hline f. /dgıld / & $\rightarrow \quad$ [d]Ild] & "leather" \\
\hline g. $/ \mathrm{s}^{\mathrm{s}} \mathrm{ffr} /$ & $\rightarrow \quad\left[\mathrm{s}^{\mathrm{s}} \mathrm{IfIr}\right]$ & "zero" \\
\hline h. /faћm / & [faћam] & "coal" \\
\hline i. /gIdr / & [gIdır] & "pot" \\
\hline
\end{tabular}

The data reveal that coda consonant clusters in QA comply with SSP, which is clearly illustrated in (e-f). Accordingly, an epenthesis is blocked in the coda clusters due to the conformity to SSP. By contrast, the coda clusters like those in (g-i) do not obey the sonority sequencing, and this violation motivates vowel epenthesis. Thus, this process exerts an impact on the syllable structure of QA, and disyllable structures result from monosyllable structures under the epenthesis process. Now, let us illustrate how the epenthesis in QA is analyzed within the framework of OT. The following constraints in Table 4 are interacted to evaluate the candidates of the input / gIdr / "pot."

Table 4. ONSET $>>$ SSP $>>$ COMPLEX $>>$ MAX-IO $>>$ DEP-IO $>>$ NO-CODA

\begin{tabular}{lllllll}
\hline$/$ gIdr $/$ & ONSET & SSP & COMPLEX & MAX-IO & DEP-IO & NO-CODA \\
\hline $\begin{array}{l}\text { a. gI.dIr } \\
\text { b. gIdr }\end{array}$ & & & & & $*$ & $*$ \\
c. gId.Ir & $!^{*}$ & & $*$ & & $*$ & $*$ \\
\hline
\end{tabular}

Table 4 shows that candidate (c) is eliminated because it fatally violates the undominated ONSET and violates the onset constraints because the second syllable begins with a vowel. As for candidate (b), it satisfies the high-ranked constraint ONSET but violates the second highest-ranking constraint SSP; thus, candidate (b) is eliminated. Ultimately, candidate (a) is selected as optimal even though it violates the low-ranked constraints DEP-IO and NO-CODA because it satisfies the high-ranked constraints.

\section{Geminate in QA}

Geminates are sequences of two identical consonants that usually share the same features. Cross-linguistically, geminates occur in specific phonetic positions, in which they tend to occur intervocalically and follow short stressed vowels (Thurgood, 1993, as cited in Abu-Abbas et al., 2011). Some languages restrict where geminates should occur. For instance, Standard Arabic and most of its modern dialects allow geminates medially and finally but not initially. However, there exist a few Arabic dialects that tend to use geminates in the word-initial position, such as Moroccan Arabic (Davis, 2014). QA, by contrast, retains the features of Arabic phonology in that geminates tend to occur in word-medial and word final positions, as seen above in (47) kabbuut "bonnet" and in (67) dzaadd "earnest." The data set reveals that QA demonstrates tautomorphemic geminates, which clearly

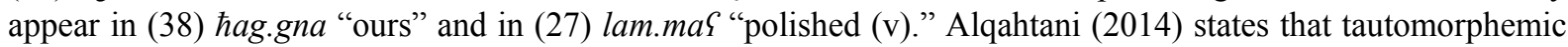
geminates are mostly found in disyllabic Arabic words. Thus, the first member of the geminate functions as a coda of the first syllable, whereas the second member functions as an onset to the following syllable. Now, let us observe how the geminates in QA are analyzed in OT. Some scholars treat geminates as long sounds/a single segment (Ladefoged \& Maddieson, 1996), whereas others treat them as a cluster of identical segments (Delattre, 1971; Abu-Abbas, 2011). Following Delattre (1971) and Abu-Abbas (2011), we treat the geminates in QA as a cluster of two identical segments. Since the two clusters are represented as two root nodes, it is better to adopt the Two-Root Theory of Selkirk $(1990,1991)$. The Two-Root Theory represents the geminates with two root nodes, which share stricture and place features, and it can differentiate between full and partial geminates (Aljumah, 2008). In Table 5 below, we analyze the geminates in QA that appear medially, as in lam.maS "polished (v)." As mentioned above, the geminates undergo syllabification in which the first [m] functions as a coda of the first syllable, whereas the second one functions as an onset of the next syllable. The following constraints are used to evaluate the candidates of the input /lamma\&/ "polished (v)." 
Table 5. ONSET $>>$ COMPLEX $>>$ MAX-IO $>>\mu]_{\sigma}$ GEM. $_{{ }_{\sigma}}[\mu>>$ DEP-IO $>>$ NO-CODA

\begin{tabular}{lllllll}
\hline llammaS/ & ONSET & COMPLEX & MAX-IO & $\mu]_{\sigma} G_{E M}{ }_{\sigma}[\mu$ & DEP-IO & NO-CODA \\
\hline a.. lam $^{\mu} \cdot m^{\mu} a S$ & & & $*$ & $*$ \\
b. lamm.aS & $* !$ & $*$ & & & $*$ \\
\hline
\end{tabular}

Table 5 illustrates that candidate (b) is eliminated because it fatally violates the undominated ONSET and also the second highest-ranking constraint COMPLEX. In other words, it violates the onset constraints because the second syllable begins with a vowel. In addition, it violates complexity due to the presence of coda clusters in the first syllable. As for candidate (a), it satisfies the high-ranked constraints ONSET, COMPLEX, and MAX-IO. Thus, candidate (a) is considered the optimal candidate with minimal violation.

\section{Conclusion}

This paper employs Optimality Theory to account for QA syllable structures. The interaction between the constraints shows that the ONSET is considered an undominated constraint in QA and is never violated, whereas NO-CODA is ranked very low.

The analysis illustrates that QA prohibits onsetless syllables. In addition, it allows complex margins (onset and coda). It is shown that QA, unlike standard Arabic, exhibits word-initial consonant clusters, which is a result of the syncope process. The syncope targets unstressed high short vowels ( $I$ and $u$ ) to create consonant clusters in the onset position. The data show that vowel deletion targets unstressed high vowels in a non-final syllable, which is preceded by the stressed syllable structure CVVC.

QA allows a complex coda in words medially or finally, as in lamb.bəh "lamp" and dzIld "leather," respectively. However, there are some coda clusters that have undergone an epenthesis repair, particularly when the clusters violate SSP. For instance, the word gIdIr "pot" comes from the underlying word gIdr "pot." Coda clusters in QA must obey the sonority sequencing principle; otherwise, epenthesis presents to repair the violation. However, no epenthesis exists in the coda clusters if they comply with the SSP: for example, galb "heart" becomes galb "heart" without any insertion.

As for the geminates, QA permits geminates medially and finally but not initially. We treat the geminates in QA as a cluster of two identical segments, and since the two clusters are represented as two root nodes, we adopt the Two-Root Theory of Selkirk $(1990,1991)$.

Finally, QA differs from MSA and CA in terms of certain structural positions. For example, CVVC appears in final and non-final positions in QA, while CVVC occurs only finally in MSA and CA. The data revealed that QA demonstrates seven fundamental syllable structures grouped into three categories: light syllables, as in $\mathrm{CV}$; heavy syllables, as in CVV and CVC; and super-heavy syllables, as in CVVC, CVCC, CCVVC, and CVVCC. In future study, we plan to enlarge the data on this dialect and focus on how the insertion of a vowel or consonant affix can impact the syllable structure of QA.

\section{References}

Abboud, P. (1979). The verb in northern Najdi Arabic. Bulletin of the School of Oriental and African Studies, 42, 467-499. https://doi.org/10.1017/S0041977X0013575X

Abdul-karaim, K. (1980). Aspects of the phonology of Lebanese Arabic. Unpublished doctoral dissertation. University of Illinois, Urbana-Champaign.

Abu-Abbas, K., Zuraiq, W., \& Abdel-Ghafer, O. (2011). Geminates and long consonants in Jordanian Arabic. International Journal of Linguistics, 3(1), E14. https://doi.org/10.5296/ijl.v3i1.735

Al-Mohanna, F. (1998). Syllabification and metrification in Urban Hijazi Arabic: Between rules and constraints. Unpublished doctoral dissertation. University of Essex.

Al-Mozainy, H. (1981). Vowel alternations in a Bedouin Hijazi Arabic dialect: Abstractness and stress. Unpublished doctoral dissertation. University of Texas at Austin.

Al-Sweel, A.-A. (1987). Verbal and nominal forms of Najdi Arabic. Anthropological Linguistics, 29(1), 71-90.

Algahtani, M. (2014). Syllable structure and related processes in Optimality Theory: An examination of Najdi Arabic. Unpublished doctoral dissertation. Newcastle University.

Alghmaiz, B. (2013). Word-initial consonant cluster patterns in the Arabic Najdi dialect. Unpublished master's thesis. Southern Illinois University-Carbondale. 
Aljumah, A. (2008). The syllable shape of the Al-Ahsa dialect: An OT perspective. Poznan Studies in Contemporary Linguistics, 44, 155-177. https://doi.org/10.2478/v10010-008-0009-8

Aquil, R. (2013). Cairne Arabic syllable structure though different phonological theories. Open Journal of Modern Linguistics, 3, 259-267. https://doi.org/10.4236/ojml.2013.33034

Benhallam, A. (1980). Syllable structure and rule types in Arabic. Unpublished doctoral dissertation. University of Florida.

Broselow, E. (1979). Cairene Arabic syllable structure. Linguistic Analysis, 5, 345-382.

Broselow, E., Huffman, M., Chen, S.-I., \& Hsieh, R. (1995). The timing structure of CVVC syllables. In M. Eid (Ed.), Perspectives on Arabic linguistics VII: Papers from the seventh annual symposium on Arabic linguistics (pp. 119-140). John Benjamins Publishing Company. https://doi.org/10.1075/cilt.130.11bro

Btoosh, M. (2006). Constraint interactions in Jordanian Arabic phonotactics: An optimality-theoretic approach. Journal of Language and Linguistics, 5(2), 102-221.

Campbell, L. (2004). Historical linguistics: An introduction (2nd ed.). MIT Press.

Clements, G., \& Keyser, S. (1983). CV phonology: A generative theory of the syllable. MIT Press.

Davis, S., \& Ragheb, M. (2014). Geminate representation in Arabic. In S. Farwaneh \& H. Ouali (Eds.), Perspectives on Arabic linguistics 24-25: Papers from the annual symposia on Arabic Linguistics (pp. 3-20). Texas, 2010 and Arizona, 2011. John Benjamins Publishing Company. https://doi.org/10.1075/sal.1.04dav

Delattre, P. (1971). Pharyngeal features in the consonants of Arabic, German, Spanish, French, and American English. Phonetica, 23, 129-155. https://doi.org/10.1159/000259336

Hamdi, R., Ghazali, S., \& Barkat-Defradas, M. (2005). Syllable structure in spoken Arabic: A comparative investigation (pp. 2245-2248). In INTERSPEECH: 9th European conference on speech communication and technology.

Ingham, B. (1994). Najdi Arabic: Central Arabian. John Benjamins Publishing Company. https://doi.org/10.1075/loall.1

Jarrah, I. (2013). Syllables and syllable structure in Arabic in the light of the Optimality Theory. Open Science Repository Language and Linguistics, e70081958. https://doi.org/10.7392/openaccess. 70081958

Kager, R. (1999). Optimality theory. Cambridge University Press. https://doi.org/10.1017/CBO9780511812408

Kaye, A., \& Daniels, P. (Eds.). (1997). Phonologies of Asia and Africa: Including the Caucausus. Eisenbrauns.

Kreidler, C. (2001). Phonology: Critical concepts (1st ed.). Routledge.

Ladefoged, P., \& Maddieson, I. (1996). The sounds of the world's languages. Blackwell.

McCarthy, J. (1979). On stress and syllabification. Linguistic Inquiry, 10, 443-465.

McCarthy, J. (2008). Doing Optimality Theory: Applying theory to data. Wiley. https://doi.org/10.1002/9781444301182

Naess, U. (2008). Gulf Pidgin Arabic: Individual strategies or structured variety. Unpublished master's thesis. University of Oslo.

Newman, D. (2008). The phonetic status of Arabic within the world's languages: The uniqueness of the lu "At Al-dAAd". Unpublished master's thesis. Newcastle University.

Qafisheh, H. (1977). A short reference grammar of Gulf Arabic. University of Arizona Press.

Rakhieh, B. (2009). The phonology of Ma'ani Arabic: Stratal or parallel OT. Unpublished doctoral dissertation. University of Essex.

Reetz, H., \& Jongman, A. (2009). Phonetics: Transcription, production, acoustics, and perception. Blackwell.

Sakarna, K. (2005). The linguistic status of the modern Jordanian dialects. Arabica, 52(4), 522-543. https://doi.org/10.1163/157005805774320231

Selkirk, E. (1990). A two-root theory of length. In J. Padgett \& E. Dunlap (Eds.), Papers in phonology (University of Massachusetts Occasional Papers 14, pp. 123-177). GLSA Publications.

Selkirk, E. (1991). On the inalterability of geminates. In P.-M. Bertinetto, M. Kenstowicz \& M. Loporcaro (Eds.), Certamen Phonologicum II (pp. 187-209). Papers from the 1990 Cortona Phonology Meeting. Sellier. 
Smolensky, P., \& Prince, A. (1993). Optimality Theory: Constraint interaction in generative grammar (Technical Report CU-CS-696-93). Department of Computer Science, University of Colorado at Boulder.

Thurgood, G. (1993). Geminates: A cross-linguistic examination. In J. Nevis, G. McMenamin \& G. Thurgood (Eds.), Papers in honor of Frederick Brengelman on the occasion of the twenty-fifth anniversary of the Department of Linguistics (pp. 129-139). California State University.

Watson, J. (2002). The phonology and morphology of Arabic. Oxford University Press.

\section{Notes}

Note 1. We use both "Classical Arabic" and "Standard Arabic" interchangeably to refer to Classical Arabic in keeping with other researchers.

Note 2. VV refers to a long vowel since Arabic prohibits two vowels in a row.

\section{Copyrights}

Copyright for this article is retained by the author, with first publication rights granted to the journal.

This is an open-access article distributed under the terms and conditions of the Creative Commons Attribution license (http://creativecommons.org/licenses/by/4.0/). 